\title{
Advantages and disadvantages of the ENVOY GF distal access guiding catheter in endovascular coiling for anterior circulation aneurysms
}

\author{
Jin Wook Baek ${ }^{1 *}$, Sung-Chul Jin ${ }^{*}$, Sung-Tae Kim², Young Jin Heo', Ji Yeon Han', Jung Hwa Seo ${ }^{3}$, \\ Sung Hwa Paeng ${ }^{2}$, Jung Soo Kim", Hae Woong Jeong', Young-Gyun Jeong ${ }^{2}$ \\ ${ }^{\prime}$ Department of Diagnostic Radiology, ${ }^{2}$ Neurosurgery, ${ }^{3}$ Neurology, Inje University Busan Paik Hospital, ${ }^{4}$ Department \\ of Neurosurgery, Inje University Haeundae Paik Hospital \\ "These authors contributed equally to this paper.
}

\begin{abstract}
Objective : Selecting an appropriate guiding catheter to provide both sufficient supportability for working devices and sufficient distal navigability is essential for ensuring the success of a procedure. This study aimed to evaluate the advantages and disadvantages of using the ENVOY 6F distal access (DA) guiding catheter in coil embolization of anterior circulation cerebral aneurysms.
\end{abstract}

Methods: We included 98 patients $(72$ [73.5\%] women, median age: 63 [range: 25-84] years) who underwent endovascular coiling with the ENVOY 6F DA guiding catheter from May to November 2016. We analyzed data on patient demographics and the number of co-axial techniques to position the guiding catheter, initial and final location of the catheter, and complications related to the catheter.

Results : The co-axial technique was used to position the ENVOY 6F DA guiding catheter in the internal carotid artery (ICA) in 20 cases $(20.41 \%)$. The initial position of the ENVOY 6F DA guiding catheter involved the cervical ICA (79.6\%), horizontal petrous ICA (17.3\%), and vertical petrous ICA (3.1\%). Final control angiograms after endovascular coiling showed proximal change in the final, compared to the initial, position of the ENVOY 6F DA guiding catheter in 25 cases $(25.51 \%)$. Procedure-related complications were observed in nine patients (9.18\%), involving vasospasm in all cases; however, there was no symptomatic case.

Conclusion : The ENVOY 6F DA guiding catheter had relatively sufficient distal navigability without symptomatic procedural complications. However, the change in the catheter position after endovascular coiling denoted insufficient supportability.

Keywords Carotid Artery, Internal, Catheterization, Intracranial Aneurysm, Cerebrovascular Circulation
J Cerebrovasc Endovasc Neurosurg. 2019 March;21(1):5-10

Received : 30 December 2018

Revised : 16 February 2019

Accepted : 18 March 2019

\author{
Correspondence to Sung-Tae Kim \\ Department of Neurosurgery, Busan Paik \\ Hospital, Inje University, College of Medicine \\ 75, Bokji-ro, Busanjin-gu, Busan, Republic of \\ Korea \\ Tel : 82-51-890-6144 \\ Fax : 82-51-898-4244 \\ E-mail : kimst015@hanmail.net \\ ORCID : http://orcid.org/0000-0002-3737-3850
}

This is an Open Access article distributed under the terms of the Creative Commons Attribution NonCommercial License /http://creativecommons.org/licenses/by-nc/3.0) which permits unrestricted censes/by-nc/3.0) which permits unrestricted nonmedium, provided the original work is properly cited.

\section{INTRODUCTION}

The selection of an appropriate guiding catheter that can provide not only sufficient supportability for working devices, but also sufficient distal navigability is essential to ensure procedural success in endovascular procedures. In the past, placing guiding catheters in the common or proximal internal carotid artery 
(ICA) had to be accomplished using rigid and thick guiding catheters that lacked sufficient distal navigability and had the potential risk of inducing carotid artery injury, such as dissection or vasospasm. ${ }^{14)}$ With the continuous improvement of materials, various attempts have been made to develop a system where guiding catheters can be localized closer to the lesion with good supportability and safety. ${ }^{178)(15)}$ The practical usefulness of new devices, such as intermediate catheters, has been proven in several studies. ${ }^{34) 13) 14)}$ However, these intermediate guiding systems require co-axial double guiding or exchange techniques for positioning guiding catheters. A newly-designed guiding catheter, the ENVOY 6F distal access (DA) guiding catheter (Codman Neuro, Raynham, MA), is expected to have high distal navigability and sufficient supportability, without requiring co-axial double guiding or exchange for accurate positioning. We evaluated the distal navigability, supportability, and safety of the ENVOY 6F DA guiding catheter with no co-axial guiding system for the endovascular coiling of anterior circulating cerebral aneurysms.

\section{METHOD}

\section{Patients}

From May to November 2016, 98 patients with anterior circulating cerebral aneurysms that were treated using only the 6-F ENVOY DA guiding catheter were included in this study. We retrospectively reviewed archived angiographic runs and still images, as well as procedure reports, and analyzed baseline characteristics including age, sex, and status of aneurysmal rupture, immediate angiographic outcome according to modified Raymond Roy occlusion classification $(\mathrm{RROC}){ }^{10)}$ the location of the initial guiding catheter tip, location of the final guiding catheter tip, use of the co-axial technique to navigate the guiding catheter, and the incidence of complications to evaluate catheter performance and safety.

The carotid artery was divided into five segments, including three in the cervical ICA and two in the petrous ICA. Catheter performance was assessed by the ability to achieve distal vascular access in the carotid artery, with 1, 2, and 3 points being assigned for placement in the proximal, middle, and distal cervical ICA, respectively. The horizontal and vertical petrous portions of the ICA were assigned 4 and 5 points, respectively (Fig. 1).

\section{Procedure}

All procedures were performed via the common femoral artery access route. We did not routinely use the $125-\mathrm{cm}$ angiocatheter co-axially for the guiding

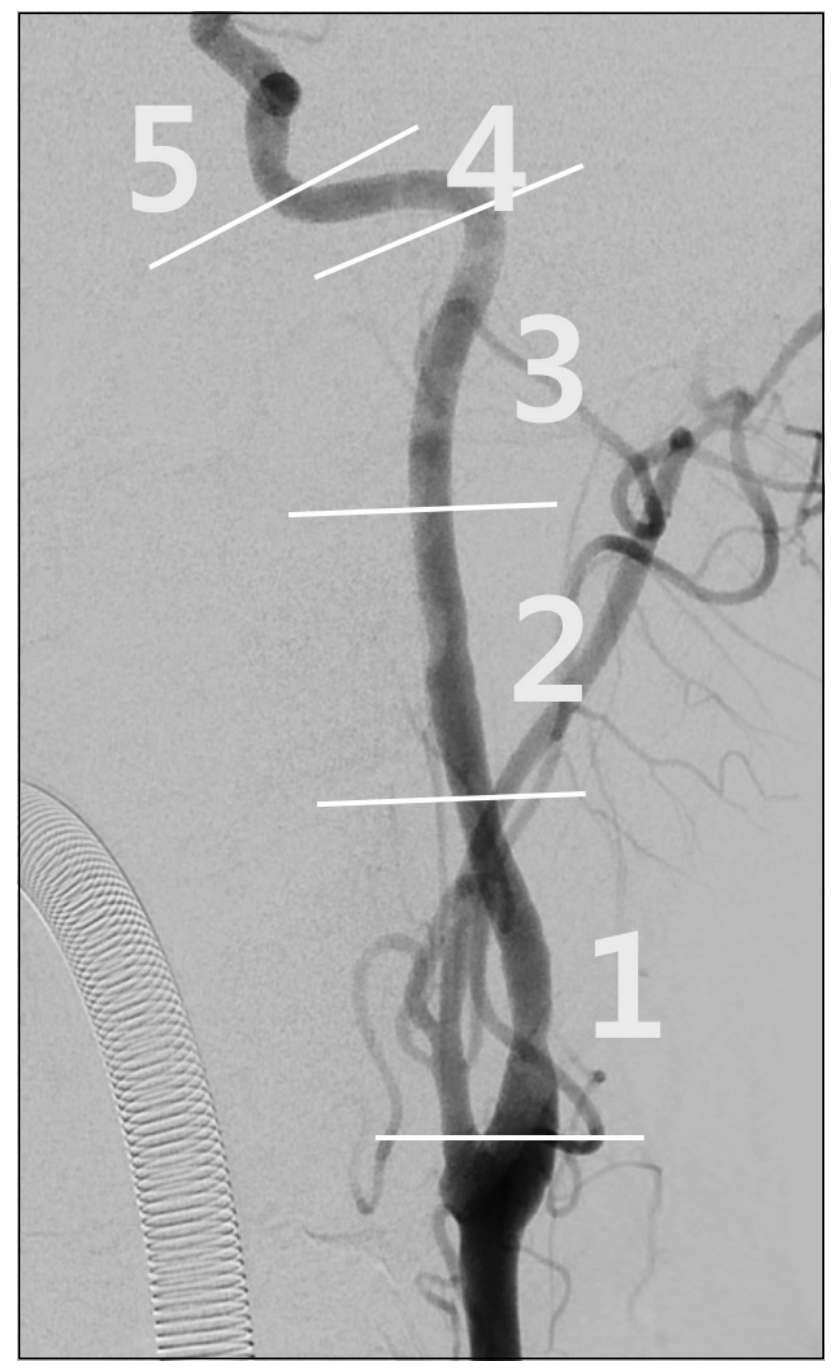

Fig. 1. Anteroposterior view of the internal carotid artery (ICA) The CA was divided into five segments. It was divided into three segments between the carotid bifurcation and the $90^{\circ}$ curve of the petrous segment, and the petrous segment was divided into two segments, a horizontal and a vertical portion. 
catheter to be selectively inserted into the right brachiocephalic trunk or left common carotid artery (CCA). A single guiding catheter without a co-axial system has been generally used in endovascular coiling of cerebral aneurysms to simplify the procedural steps and reduce heparinized flushing lines from being connected into the guiding catheter. Aneurysms were evaluated by the Integris V (Philips Medical Systems, The Netherlands) and Artis zee (Siemens Medical Solutions, Germany) biplane system, with three-dimensional rotational angiography. Patients with unruptured aneurysms were administered single- (clopidogrel) or dual-agent (clopidogrel and aspirin) antiplatelet medication in advance, depending on the results of VerifyNow P2Y12 (Accumetrics, San Diego, CA) clopidogrel resistance assays. ${ }^{6}$ Patients with ruptured aneurysms did not receive antiplatelet medication in advance. Rather, a bolus of heparin (50

Table 1. Baseline characteristics of patients

\begin{tabular}{lc}
\hline Age (Median yrs. (range)) & 63 \\
\hline Sex & \\
Male & $26-84)$ \\
Female & 72 \\
Status of rupture & \\
Unruptured aneurysm & 61 \\
Ruptured aneurysm & 37 \\
Immediate angiographic outcome & \\
Complete & 22 \\
Residual Neck & 67 \\
Residual Sac & 8 \\
Failed procedure & 1 \\
\hline
\end{tabular}

Table 2. Initial and final location of the guiding catheter tip

\begin{tabular}{lcc}
\hline & Initial Location & Final Location \\
\hline Cervical ICA 1 & 2 & 4 \\
Cervical ICA 2 & 9 & 20 \\
Cervical ICA 3 & 67 & 62 \\
Horizontal Petrous ICA & 17 & 11 \\
Vertical Petrous ICA & 3 & 1 \\
\hline Total & \multicolumn{3}{c}{98} \\
\hline
\end{tabular}

Table 3. Number of cases requiring the co-axial technique for navigation and the incidence of complications

\begin{tabular}{lc}
\hline & ENVOY 6F DA (N=98) \\
\hline Use of co-axial technique & $20(20.41 \%)$ \\
Complication & $9(9.18 \%)$ \\
\hline
\end{tabular}

$\mathrm{IU} / \mathrm{kg}$ ) was injected via the venous route when the operator considered that the rupture point was completely protected.

\section{RESULTS}

The baseline characteristics of the patients are described in Table 1. The median age was 63 (range: $25-84)$ years. There were 72 women $(73.47 \%)$, and 61 (62.24\%) patients had unruptured aneurysms.

The ENVOY 6F DA guiding catheter was successfully placed in the internal carotid artery on the side of the lesion without failure. Among the 98 cases, the co-axial technique was required in 20 cases $(20.4 \%)$. The $125-\mathrm{cm}$ angiocatheter used in the co-axial system included the VTK (16 cases), Headhunter (two cases), and Bern (two cases) catheters.

The initial location of the guiding catheter tip prior to coil embolization and final location of the guiding catheter tip after coil embolization were described in Table 2 . The guiding catheter moved proximally from the initial position in 25 cases (25.51\%).

Procedure-related complications during the positioning of the guiding catheter were identified in nine cases $(9.18 \%)$ and all involved vasospasm that showed spontaneous improvement in blood flow, exhibiting no vascular abnormal findings on delayed follow-up angiography. Therefore, there was no procedural symptomatic morbidity.

The immediate post-procedural radiological outcomes are described in Table 1. Twenty-two cases (22.45\%) showed complete occlusion, 67 (68.37\%) showed remnant neck, and eight (8.16\%) showed remnant sac, according to the modified RROC during immediate post-procedural angiography. ${ }^{10)}$ In one case, coil embolization failed. In this case, during coil embolization, the coil and coil delivery microcatheter were not separated. While trying to separate the coil and microcatheter, they simultaneously exited the aneurysm, and a thrombus was formed inside the sac. However, in that case, the guiding catheter was well placed. 


\section{DISCUSSION}

An ideal guiding catheter system should have sufficient navigability to be placed as close as possible to the target lesion to reduce the working length of the microcatheter or microwire without procedural complications. It should also have sufficient supportability to allow use of the device. ${ }^{3) 4)}$ However, designing a guiding catheter system that has good navigability and supportability would be difficult because good navigability requires device softness and might conflict with good supportability that requires device stiffness. ${ }^{9)}$ Conventionally, to achieve proper levels of supporting power and navigability, we have used numerous techniques, such as a "buddy" wire, co-axial double guiding catheters, or changing of the access route. ${ }^{12) 8) 11) 12) 15) 16) ~ T h e s e ~ t e c h n i q u e s ~ r e q u i r e ~ m a n y ~ d e-~}$ vices and additional procedural steps and involve a high risk of complications, such as vasospasm, artery wall dissection, air embolism, and embolic infarction. ${ }^{8)}$

Unlike previous guiding catheters, the ENVOY $6 \mathrm{~F}$ DA guiding catheter has an 8 -cm distal flexible segment that can likely improve distal navigability in more tortuous vessels. The co-axial technique using the 125-cm angiocatheter for placing the guiding catheter was used in 20 cases (20.4\%). This may be attributed to the flexibility of the distal segment of the ENVOY 6F DA guiding catheter, which renders it less stable while navigating the guidewire into the carotid artery because of the angle between the aortic arch and the right brachiocephalic trunk or left CCA. Therefore, in the lesions with acute angles between the aortic arch and the right brachiocephalic trunk or left CCA, the co-axial technique with an additional catheter should be considered for using the ENVOY 6F DA guiding catheter.

In our series, positioning of the ENVOY 6F DA guiding catheter involved the distal cervical ICA (cervical ICA C3, $n=62(63.3 \%)$ ) and petrous ICA $(n=12,12.2 \%)$ (Fig. 2). This result signifies that the navigability of the ENVOY $6 \mathrm{~F}$ DA guiding catheter is superior to that of traditional guiding catheters but inferior to that of other new generated intermediate catheters, such as SOFIA (Soft torqueable catheter Optimized for Intracranial Access, MicroVention Inc, Tustin, CA) and Catalyst (Stryker Neurovascular, Fremont, CA). ${ }^{12)}$ Accordingly, in tortuous vasculatures that have a redundant working length, an intermediate catheter rather than the ENVOY 6F DA guiding catheter would be better for distal navigability.

Differences between the initial and final location of the guiding catheter tip, reflecting the supportability of the guiding catheter, were noted in 25 cases $(25.5 \%)$. This may be attributable to inevitable decrease in supporting forces due to structural differences. ${ }^{5)}$ In this regard, the authors' experience shows that the more complicated the procedure is, for example, as the number of devices used increases, the more the guiding catheter is draw back during the procedure due to this lack of support.

Based on our results, the distal navigability of the ENVOY 6F DA guiding catheter without a co-axial guiding system will be superior to that of traditional guiding system but inferior to that of newly-designed intermediate catheters. The supportability of the ENVOY 6F DA guiding catheter without a co-axial guiding system will be superior to that of intermediate catheters but inferior to that of traditional guiding catheters. However, an intermediate catheter will generally use a co-axial guiding system to overcome the insufficient supportability of intermediate catheters. Therefore, the ENVOY DA $6 \mathrm{~F}$ guiding catheter without a co-axial system will not be considered practically useful for all cases of anterior circulation aneurysms. To prevent or overcome the insufficient supportability of the ENVOY DA 6F guiding catheter, a co-axial guiding catheter system will be considered in tortuous vasculatures.

This study has some limitations. This was a single-center retrospective study, and it is possible that there was selection bias with regard to the included cases, although we enrolled consecutive patients. 


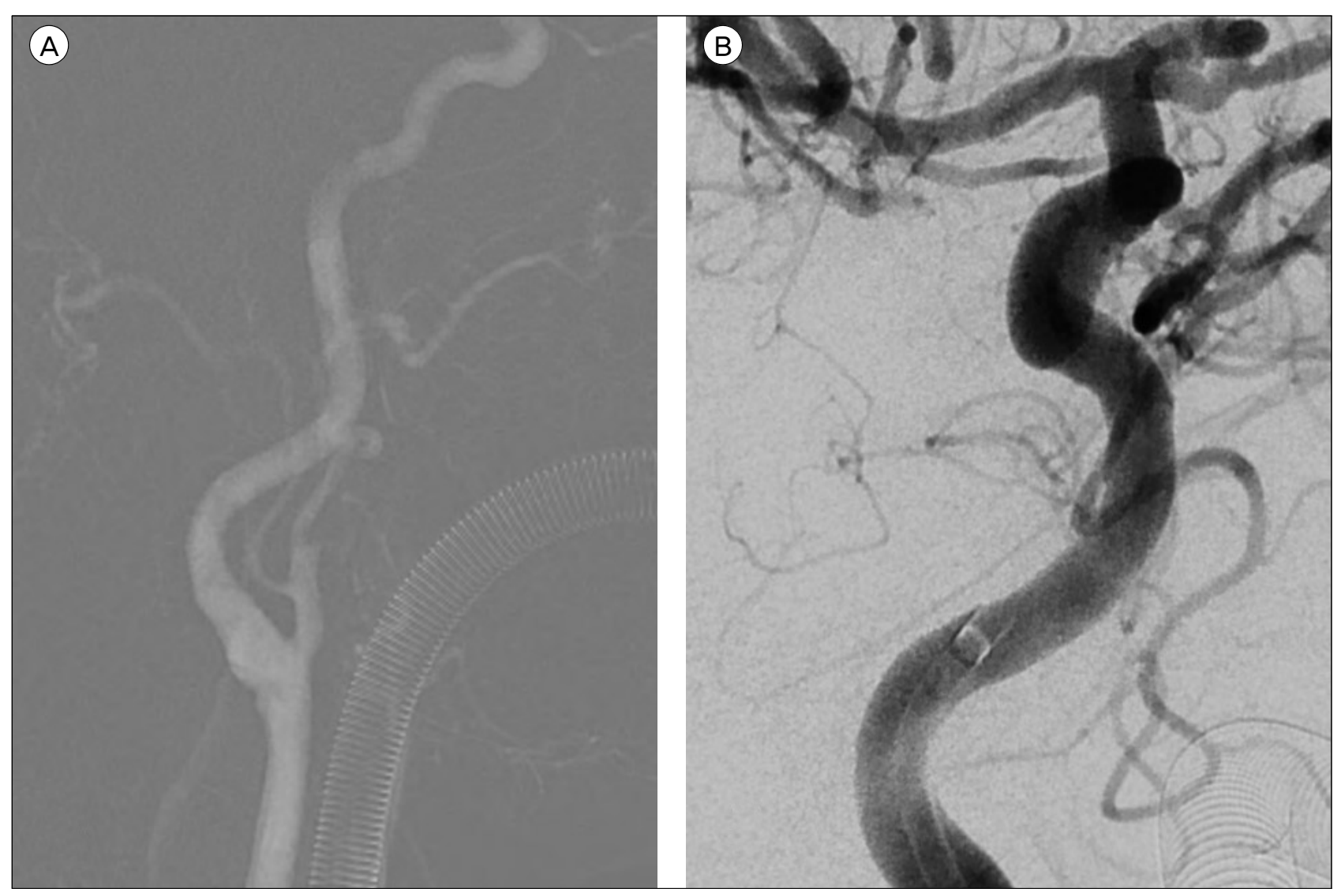

Fig. 2. Illustrative case. A woman aged 77 years with acute subarachnoid hemorrhage and a ruptured anterior communicating artery aneurysm underwent right internal carotid artery (ICA) angiography. (A) There were two acute turns on the right ICA roadmap image. (B) After careful navigation, the ENVOY 6F DA guiding catheter was located at the vertical petrous segment (segment number 4 according to our classification) without any complications on right ICA angiography.

Moreover, we attempted to control other variables that could possibly affect the outcome of the procedure, such as tortuosity of the ICA. However, other factors remain that could have possibly affected the outcome, such as operator-related differences. Therefore, to overcome these limitations, additional prospective, multicenter studies are needed.

\section{CONCLUSION}

In our series, the ENVOY 6F DA guiding catheter had relatively sufficient distal navigability without symptomatic procedural complications. However, changes in catheter position after endovascular coiling denoted that supportability was insufficient.

\section{ACKNOWLEDGMENTS}

This study was supported by a grant from WITH HealthCare.co., Ltd.

\section{REFERENCES}

1. Bendok BR, Przybylo JH, Parkinson R, Hu Y, Awad IA, Batjer HH. Neuroendovascular interventions for intracranial posterior circulation disease via the transradial approach: technical case report. Neurosurgery. 2005;56(3): E626-E.

2. Blanc R, Piotin M, Mounayer C, Spelle L, Moret J. Direct cervical arterial access for intracranial endovascular treatment. Neuroradiology. 2006;48(12):925-9.

3. Chandran A, Puthuran M, Eldridge PR, Nahser HC. Distal access using hyperflexible atraumatic distal tip with optimized proximal stability of the Benchmark intracranial guide catheter for the treatment of cerebral vascular diseases: a technical note. Journal of neuro- 
interventional surgery. 2016;8(7):718-21.

4. Hui FK, Schuette AJ, Spiotta AM, Yim J, Obuchowski $\mathrm{N}$, Rasmussen PA, et al. Flexible tip guides and intermediate catheters: two center experience and a proposed taxonomy. Journal of neurointerventional surgery. 2014;6(8):618-23.

5. Imaoka T, Itoh K. Analysis of the Properties of Guiding Catheters Used in Endovascular Neurointervention. Interventional Neuroradiology. 2007;13(1_suppl):58-63.

6. Kang H-S, Kwon B, Kim JE, Han MH. Preinterventional clopidogrel response variability for coil embolization of intracranial aneurysms: clinical implications. American Journal of Neuroradiology. 2010;31(7):1206-10.

7. Koenigsberg RA, Aletich V, Camras L, Debrun G, Ausman J. Direct cervical internal carotid access for GDC treatment of an ophthalmic origin carotid aneurysm. Surgical neurology. 1999;51(5):506-8.

8. Lee $\mathrm{TH}$, Choi $\mathrm{CH}$, Park K-P, Sung SM, Lee SW, Lee $\mathrm{B}-\mathrm{H}$, et al. Techniques for intracranial stent navigation in patients with tortuous vessels. American Journal of Neuroradiology. 2005;26(6):1375-80.

9. Linfante I, Wakhloo AK. Brain aneurysms and arteriovenous malformations: advancements and emerging treatments in endovascular embolization. Stroke. 2007;38(4):1411-7.

10. Mascitelli JR, Moyle H, Oermann EK, Polykarpou MF, Patel AA, Doshi AH, et al. An update to the
Raymond-Roy Occlusion Classification of intracranial aneurysms treated with coil embolization. Journal of neurointerventional surgery. 2015;7(7):496-502.

11. Nii K, Kazekawa K, Onizuka M, Aikawa H, Tsutsumi M, Tomokiyo M, et al. Direct carotid puncture for the endovascular treatment of anterior circulation aneurysms. American Journal of Neuroradiology. 2006;27(7):1502-4.

12. Simon SD, Ulm AJ, Russo A, Albanese E, Mericle RA. Distal intracranial catheterization of patients with tortuous vascular anatomy using a new hybrid guide catheter. Surgical neurology. 2009;72(6):737-40.

13. Spiotta AM, Hussain MS, Sivapatham T, Bain M, Gupta $\mathrm{R}$, Moskowitz SI, et al. The versatile distal access catheter: the Cleveland Clinic experience. Neurosurgery. 2011; 68(6):1677-86.

14. Turk A, Manzoor MU, Nyberg EM, Turner RD, Chaudry I. Initial experience with distal guide catheter placement in the treatment of cerebrovascular disease: clinical safety and efficacy. Journal of neurointerventional surgery. 2013;5(3):247-52.

15. White JB, Kallmes DF. Utility of the "buddy" wire in intracranial procedures. Neuroradiology. 2008;50(2):185-7.

16. Yuzawa I, Kurata A, Suzuki S, Ozawa H, Hagiwara H, Niki J, et al. Efficacy of a direct puncture approach for anterior circulation aneurysms using a newly developed guiding catheter-especially for geriatric patients. Surgical neurology. 2007;67(1):30-4. 